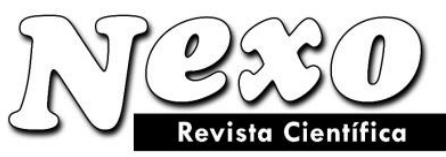

\title{
EDITORIAL UDEFAL
}

\section{Arquitectura e ingeniería para ciudades saludables en américa latina y el caribe}

\author{
Alfredo Otero Ortega ${ }^{1}$
}

Numerosos, son los temas que se pueden tratar desde los saberes de la ingeniería y sus múltiples disciplinas. El diseño de obras civiles e infraestructura con una estética que de valor al paisaje urbano; el desarrollo de tecnologías que conecte los espacios urbanos con las personas y la producción de materiales amigables. Así mismo una oferta de servicios desde la arquitectura para mediar en la superación de brechas urbanas y del diseño de objetos edilicios articulados a un espacio público generoso que haga menos difícil el vivir saludable como ciudadanos de este siglo XXI en las ciudades de América Latina y el Caribe.

La Arquitectura y la Ingeniería no han estado por fuera de la crisis pandémica que de manera abrupta nos sorprendió desde finales del año 2019. Este virus denominado COVID - 19 quito el velo a numerosas situaciones que, si bien algunas eran conocidas por muchas personas, estas no se habían enfrentado con la realidad que nos ha impuesto esta pandemia, la cual irrumpió en las perspectivas sociales, económicas y culturales de los habitantes del planeta.

Esto nos debe llevar a re-aprender los saberes que abordamos desde nuestras disciplinas académicas y científicas. Revisar las practicas del ejercicio de la planificación del territorio y re-pensar los diverso sistemas constructivos y tecnológicos que se hace necesario utilizar para llevar a cabo la construcción de ciudad y obras civiles. Hoy más que nunca el compromiso con los objetivos del desarrollo sostenible (ODS) cobran importancia para los gobiernos mundiales, por lo tanto, los profesionales de la arquitectura y la ingeniería deben ser protagonistas de estos procesos de cambio que necesita la nueva realidad planetaria postpandemia.

Entendiendo estos acontecimientos, este número especial de Nexo Revista Científica presenta una edición temática desde diversas miradas, donde los autores proponen en cada uno de sus textos, una perspectiva del quehacer de la arquitectura y la ingeniería como búsqueda de solución a los problemas que presenta la ciudad. Se ha realizado una selección de trabajos a partir de los muchos que llegaron a través de la convocatoria abierta que se realizó desde la dirección de investigaciones de Universidad Nacional de Ingeniería.

Valoramos la cantidad de artículos recibidos y su variedad en cuanto a temas presentados: la dicotomía educacional de la arquitectura y su clasificación en el campo de la educación; la

1 Editor Principal Número Especial Nexo Revista Científica. Arquitecto - Urbanista. Dr. Architecture \& Urban Studies, Urban \& Regional Researc. Director de Investigación y vicepresidente adjunto de la Región Andina de la UDEFAL. Miembro de la Sociedad Colombiana de Arquitectos, SCA y de la Asociación Colombiana de Investigadores Urbano Regionales, ACIUR. Profesor - Investigador de la Universidad del Atlántico, Colombia. 
búsqueda de alternativas para los sistemas de mampostería y la producción de nuevo material. Rehabilitar los inmuebles de nuestras ciudades son parte de las preocupaciones de los investigadores urbanos y arquitectónicos, quienes se ocupan por mantener las condiciones primigenias de los mismos como valor cultural. El marketing como estrategia para posesionar la ciudad en los mercados mundiales se ha convertido en uno de los objetivos de cara a la reactivación económica. La producción de arquitectura urbana desde la practica cultural y los diseños paramétricos y el mundo digital como solución a los problemas del territorio son también temas de investigación.

Esto nos da una muestra de la producción de conocimiento que se está dando en muchas universidades del continente americano y en especial en las Facultades y Escuelas de Ingeniería y Arquitectura. Encontramos textos con una calidad conceptual y empírica por los resultados que muestran en su abordaje temático. Se reconoce una variada procedencia desde diferentes contextos geográficos (Colombia, Guatemala, México, Nicaragua, Panamá, República Dominicana). Artículos que abren un debate crítico y propositivo sobre el papel de la Ingeniería y la Arquitectura en las ciudades latinoamericanas y caribeñas. 